where the intra-pericardial pressure was atmospheric, and the thymus, which was nine inches long, extending downwards over the pericardium. There was no evidence of injury or of inflammation.

The association of this marked enlargement with the disappearance of the negative pressure in the pericardium is, it seems to me, a point of great interest and importance, for it raises the question whether this enlargement was responsible for the change in the pressure. If this was a case of status lymphaticus then the further question arises whether in all cases of status lymphaticus the intra-pericardial pressure is disturbed in this way. Normally the intra-pericardial pressure is negative in order to secure a suction action whereby the fluid is kept at an equal thickness all over the surface of the heart. This evenly-spread fluid is of great importance for purposes of lubrication, and any variation in the pressure disturbs the lubrication. Is this disturbance of lubrication in status lymphaticus responsible for the sudden cessation of the heart's action?

2. Ruptured Heart.-A well-built lad, aged 16, was standing near a crane from which was suspended a heavy steel tube. As the tube was lowered it pressed against his chest and abdomen; he then stepped back a few paces and fell down, dead. Post-mortem examination showed the intra-pericardial pressure was atmospheric, and on opening the sac it was found to be full of blood. In the right auricle was a tear one inch long. Was this due to the back pressure caused by the tube pressing on his abdomen?

3. Ruptured Superior Vena Cava.-A man, aged 42, was found dead in a cellar into which he had fallen through a man-hole. Post-mortem examination showed the sternum to be fractured at the sternal angle. On opening the chest a marked extravasation of blood was found behind the seat of the fracture due to a tear in the superior vena cava. There was no marked engorgement of the veins of the head and neck; the left side of the heart was full.

With regard to the third case, was death due to shock, or to the extravasated blood pressing so heavily on the aorta as to block its passage?

$$
\text { A CASE OF }
$$

POTT'S DISEASE ASSOCIATED WITH INJURY.

Bу F. Bedo Ноbbs, M.B., B.СН. Самв., D.P.H., RESIDENT MEDICAL OFFICER, CITY OF LONDON HOSPITAL FOR DISEASES OF THE CHEST.

Is view of the recent discussion on the relationship of tuberculosis and injury, ${ }^{1}$ the following case appears to be of some interest, owing to the clear connexion between the onset of spinal caries and injury to the vertebral column three weeks previously.

The patient, a male aged 19, was admitted to hospital on May 1st, 1922, complaining of pain in the right side of the chest and neck.

History.-There was no family history of tuberculosis, and his previous health had always been good. In August, 1921, while carrying out his occupation of boiler cleaning, he fell and injured his back. Three weeks later he complained of stiffness in the back, and was unable to bend down without pain. Thereafter pain in the right side of the chest was a constant symptom, later affecting both sides and occurring also in the back of the neck. He had to cease work in October, 1921, and later took to his bed. He attended the local tuberculosis dispensary in November, and was sent to this hospital in May, 1922 .

Condition on Examination.-The patient was very emaciated and lay in a very rigid position in bed. When sitting up, which he was only able to do with difficulty, he supported his head with his hands in the characteristic attitude, and was very sensitive to the slightest jarring. In the neck there was marked tenderness over the second and third cervical vertebræ, while in the mid-thoracic region there was a definite falling-in of the vertebræ. In the chest no abnormal physical signs could be detected.

$X$ Ray Examination (May 9th, 1922).-This showed a large abscess $12 \mathrm{~cm}$. in diameter, extending from the
fourth to the eleventh dorsal vertebra, together with partial collapse of the bodies of the ninth and tenth dorsal vertehre There was no evidence of disease of the cervical vertebra.

Operations.-On June 30th the abscess was evacuated posteriorly by a paravertebral incision and removal of the vertebral end of the ninth rib on the left side. A bout a pint of caseous pus was evacuated, iodoform emulsion inserted, the wound closed, and the patient put into a plaster jacket. A month later the patient developed a retropharyngeal abscess which was opened posteriorly to the sternomastoid.

The wound in the back eventually broke down completely and discharged freely, the patient gradually became weaker and died on Sept. 20 th, 1922.

Post-mortem Examination.-Dr. S. Roodhouse Gloyne found two separate and distinct tuberculous lesions: (1) The second cervical vertebra was extensively necrosed, leaving second cervicall of bone. The wings of the atlas were also very roughened. From the situation and extent of the lesion it was remarkable that sudden death had not occurred from dislocation. (2) All the vertebræ from the seventh to twelfth dorsal inclusive were involved in a tuberculous process, the ninth, tenth, and eleventh being almost completely disintegrated and only held in position by the surrounding ligaments. Indeed, there was so much rotation of the ninth vertebra that the transverse process on the right side was projecting through the skin.

A remarkable feature was the way in which the eighth, ninth, tenth, and eleventh ribs on the right side had become detached from their corresponding vertebræ and fallen inwards, the ninth being completely separated from the vertebral column. The same thing was found to have occurred with the eighth, tenth, eleventh, and twelfth ribs on the left side, the vertebral end of the ninth having been removed by operation previously. In addition, caseous tuberculous deposits were noted at the junction of the seventh rib with the transverse process. A large abscess containing caseous pus was found tracking down beneath the psoas muscle on each side. Apart from some very recent miliary tubercles in the lung, no other tuberculous lesions were found in the glands or viscera, but lardaceous disease was present.

Very few authenticated cases of spinal caries following injury appear to have been reported. This case falls into the second group of cases referred to by Tattersall, in which tuberculosis has rapidly supervened after injury, in an individual showing no obvious pre-existing tuberculous focus. It is difficult to say whether the injury had lighted up some lesion localised in the vertebræ, or whether a latent tuberculosis in some other part of the body-though none was found post mortem-was stirred up by the injury. ${ }^{2}$ In any case the relation of injury to the disease appears more than a coincidence.

The other points of interest in this case were : (1) The occurrence of two separate tuberculous lesions in the vertebral column (at the Royal National Orthopædic Hospital, only nine cases of double gibbosity of the spine were observed in 19 years $^{3}$ ): (2) the rarity of caries of the first and second cervical vertebræ stated by C. M. Richards ${ }^{4}$ to be the vertebra least frequently affected ; (3) the remarkable manner in which the lower ribs had become detached from the vertebræ.

I am indebted to Dr. Arnold Chaplin, under whose care the case was, for permission to publish these notes.

References. - 1. Tattersall, N. : The Relationship of Tuberculosis and Injury, Tubercle, June, 1922. 2. Oliver, Sir May 29th 1915. 3. Tubby, Tuberculosis, Brit, Med. Jour., Diseases of the Bones and Joints, 1912, p. 63. 4. Richards, C. M. : Suboccipital Pott's Disease, Amer. Jour. Roentgenology, 1921, viii., 632

\section{A CASE OF ORAL SEPSIS.}

\section{By G. Steele-Perkins, M.D. Edin.}

ON Dec. 12th Sir William Willcox read an interesting paper on the above subject at the Medical Society of London, and as oral sepsis is at present attracting much attention, the following case should, I think, prove of interest.

Some years ago I was consulted about a young girl whose health had much deteriorated; she suffered from loss of flesh and strength, anæmia, depression, and impairment of memory, and had no interest in games such as golf, tennis, hockey, \&c., of which she had previously been very fond. On inquiry I found she had had two slight "fainting" attacks, the second rather worse than the first. These on investigation I felt sure were epileptic, and gave instructiong 
that if she had any further attacks I was to be sent for at once. Nothing was wrong with her except pyorrhors affecting practically all her teeth. Tonics, fresh air, good food, and placing her in the hands of a well-known and competent dental surgeon to deal with the pyorrhoea was the treatment adopted.

In about a fortnight she had a severe epileptic fit, the latter part of which $I$ witnessed. $\Lambda$ few weeks later a very severe epileptic fit, which $I$ also witnessed, took place, and which left her dazed and semi-conscious for several hours, and it was many hours before she regained her usual normal condition. As the dentist was obviously making no progress with the pyorrhoea I decided to have all her teeth extracted. This was done in three sittings, under gas, at intervals of four days. Within a week the patient began to improve; in a month she was a totally different girl, and in three to four months had regained all her previous good health, love of games, excellent memory, interest in life, and was a splendid specimen of a young healthy English woman.

The above happened in 1907,15 years ago. The patient has remained in excellent health ever since, did splendid work all through the war, and continues her work now simply for the love of it as financially there is no need for her to do so. She never had another fit after the teeth were removed. Her good health and her work enabled her to bear up and win through, although she lost her only brother, of whom she was intensely fond, in the early weeks of the war.

To my mind two facts stand out: (1) oral sepsis as one of the causes of epilepsy, and (2) the value of work for the maintenance of health and happiness.

\section{Antedical Societies.}

\section{ROYAL ACADEMY OF MEDICINE IN IRELAND : SURGICAL SECTION.}

A Menting of this section of the Royal Academy of Medicine was held on Dec. 15th, Sir WrLltam I. DF CoURCY WheELER, the President, in the chair.

Mr. J. B. Story showed two cases of

\section{Suspected Pituitary Tumour.}

The first was a woman, who complained of headaches and vomiting. Urine was normal and vision good, though optic neuritis was found in both eyes. W.R. was negative. X ray report was " pituitary tumour." The second case was a man, whose vision was even better than that of Case 1. W.R. negative. The X ray report was " pituitary tumour."

Dr. W. M. CROFToN commented on the absence of any signs of hyperpituitarism in either of the patients, and asked what was the connexion between the visual signs and pituitary tumour.

Mr. A. K. HENRY said that in pictures of pituitary tumours it was noticeable that the tumours as well as eroding the fossa, grew out of it and rose up into the fork between the optic nerves, pressing on them. Unless there were unilateral or bilateral visual sign he thought it dangerous to make the diagnosis of pituitary tumour. As regards treatment, he was of opinion that these cases should be treated by $X$ rays first, and if they failed operative treatment should be considered.

Dr. J. Speares said that he hoped Mr. Story would get the sugar tolerance of these patients taken, as it would be of use in diagnosis.

Mr. H. STokes expressed the opinion that the $X$ ray diagnosis of enlargement of the sella turcica should be based not on one plate, but on several, including stereoscopic plates.

Mr. SToRy, in reply, said that he could not be certain of these cases being of pituitary tumour; he had not yet completed his diagnosis.

Mr. $\mathbf{W}$. Doourn read a paper on some

Unsatisfactory Appendicectomies.

The so-called appendicular dyspepsias cover a varied group of living pathological changes, whose differential diagnosis is not always easy. For many of these patients, appendicoctomy, whilst technically casy of accomplishment, fails to relieve symptoms: further, many appendices are removed without there being sufficient pathological justification for the operation. In the out-patient department at St. Vincent's, of 29 patients who had undergone appendicectomy, either there or clsewhere, for the relief of "chronic appendicitis," 20 had been completely relieved of their symptoms by the operation, but in nine cases symptoms persisted after operation. The majority of the unsatisfactory results were in female subjects (eight, to one male). Eight of these were admitted to hospital for further study, and a second operation showed the continuation of trouble to be due in three cases to cæcum mobile, in three to tubercle, and in two to pericolitis. Detailed notes of the cases given. $\Lambda$ common pre-operative syndrome is to be found in the case-histories presented by these patients, consisting of indigestion, constipation, inconstant pains situated below or to the right of the umbilicus; tenderness over McBurney's point is inconstant; in many women a painful flatulence is a dominant complaint. The whole symptom-complex is an unsatisfactory one upon which to recommend appendicectomy offhand. Other observers, notably Gibson, of New York, and Enriquet, of Paris, have reported anything from 25 per cent. to 40 per cent. of bad end-results following appendicectomy in such cases. Four different types of living pathology might be found responsible for such symptoms, viz.: (1) chronic appendicitis, secondary to an acute attack, which was relieved without operation; (2) appendicitis chronic from the start, and unassociated with other intra-abdominal pathological change; (3) chronic appendicular pathology accompanying pathological changes in stomach, duodenum, gall-bladder, \&c. (4) lesions of ileum, cæcum, and colon, such as Lane's kink, mobile cæcum, cæcocoloptosis, pericolitis, \&c. It was not justifiable to recommend operation on the case-history and clinical examination alone in such cases ; before operating on an alleged "chronic appendix" a complete abdominal diagnosis should be made, based on combined clinical, $X$ ray, and hæmatological findings, as recommended by the Paris School of Surgery. In Mr. Doolin's opinion, the McBurney "gridiron" incision was responsible for many incomplete operations, and should not be taught to students. A large incision, properly placed and cared for, would heal just as quickly, and throw more light on the living pathology under the operator's hand.

\section{Discussion.}

The President said that there was very little to be learnt from operative success, but there was a great deal to be learnt by mistakes. $\mathrm{He}$ disliked the term appendix dyspepsia. Mr. Doolin had mentioned exploratory laparotomy. The President said that it was his custom to exhaust all possible aids to diagnosis before operating, and to make at least a provisional diagnosis before opening the abdomen.

Mr. A. Chance said that, in view of the accepted fact that the diagnosis of chronic appendicitis was not to be made with certainty from the clinical findings, the history of the case, or the $X$ ray findings, an exploratory laparotomy was not, in his opinion, infrequently necessary.

Dr. CRofTon said that he was not surprised that so many failures occurred, as in a great many cases no thought was taken of the infecting organism. He was of opinion that the surgeons themselves should do immunisations and not leave them to be done by physicians.

Mr. A. A. McConnelL said that in his opinion the end-results of this sort were not sufficiently studied. If an operation was not indicated it would do no good, in fact it would probably do harm. If the diagnosis of a case was not known before operation, he was of opinion that it would not be known after operation. At operation it was sometimes difficult 